\title{
Clinical Assessment and Cytomorphometric Analysis of Buccal Mucosal Cells in Behçet's Disease Patients
}

\author{
Dalya Mohammed B.D.S., MSc ${ }^{(1)}$ \\ Layla Sabri Yas B.D.S., MSc (Oral Pathology) ${ }^{(2)}$
}

\begin{abstract}
Background: Behçet's disease (BD) is a disorder of systemic inflammatory condition. Its important features are represented by recurrent oral, genital ulcerations and eye lesions.

Aims. The purpose of the current study was to evaluate and compare cytological changes using morphometric analysis of the exfoliated buccal mucosal cells in Behçet's disease patients and healthy controls, and to evaluate the clinical characteristics of Behçet's disease.

Methods. Twenty five Behçet's disease patients have been compared to 25 healthy volunteers as a control group. Papanicolaou stain was used for staining the smears taken from buccal epithelial cells to be analyzed cytomorphometrically. The image analysis software has been used to evaluate cytoplasmic, nuclear areas and the nuclear/cytoplasmic ratio (N/C).

Results. The cytoplasmic and nuclear area of buccal cells of Behçet's disease cases were significantly smaller than those of healthy volunteers. However, the N/C ratio remained the same when compared between both groups. All patients had recurrent oral ulcer and none of the patient had cardiac and pulmonary symptoms.

Conclusion. Cytomorphometric analysis and exfoliative cytology techniques have the ability to detect the alterations in buccal epithelial cells caused by Behçet's disease.
\end{abstract}

Key words. Behçet's disease, Cytomorphometric analysis, exfoliative cytology. (Received 2/1/2018; Accepted 11/2/2018)

\section{INTRODUCTIONS}

Behçet's disease (BD) is a systemic disease of inflammatory condition, whose causes are still vague. The clinical features of $\mathrm{BD}$ include aphthous stomatitis, genital aphthosis, uveitis, cutaneous lesions, arthritis, all types of vessels, Central Nervous System (CNS) involvement, genitourinary, gastrointestinal, pulmonary, and renal involvement ${ }^{(1)}$. The most commonlypresented features of the disease are oral and genital lesions ${ }^{(2)}$. Aphthous stomatitis appears initially in about $70 \%$ of BD patients ${ }^{(3)}$.

The disease may start with one, if not more, of the above-mentioned symptoms whereas it takes years for other symptoms to turn up gradually ${ }^{(1)}$. Regardless of the eyes, its course has been characterized by re-current episodes limiting by itself of inflammation resulting in remarkably disabled cases ${ }^{(4)}$.

The disease can be seen all over the world, recording the highest in Asia, the Middle East, and the Mediterranean region. The average age of starting point with BD is on the third decade of patient's life taking in consideration that the ratio of male to female is variable according to ethnicity ${ }^{(4)}$.

The range of male-to-female BD cases is "1:1$\left.3: 1^{\prime \prime}\right)^{(5)}$. The dilemma of the disease is noticed in the early years of its course, and in many cases takes years to appear, most of mortality rates of

(1) Master Student, Oral medicine, Department of Oral Diagnosis, College of Dentistry/ University of Baghdad, Iraq.

(2) Assistant Professor, Department of Oral Pathology Dentistry, College of Dentistry, University of Baghdad.
BD had been accounted for vascular and neurological involvements and can seldom appear for the first time as it takes time to turn up (6).

The etiology of BD had been the result of both of environmental and genetic factors in most of the complicated diseases $\left({ }^{7}\right.$.

A variety of diagnostic classifications and criteria have been suggested during the years ${ }^{(8)}$. As there are no pathognomonic clinical or laboratory findings for $\mathrm{BD}$, it must be diagnosed upon clinical grounds according to the international Criteria for Behcets disease (ICBD), Table 1

Table 1: International Study Group criteria for the diagnosis of Clinical manifestation Point ${ }^{(3)}$.

\begin{tabular}{|l|l|}
\hline Oral aphthosis & 2 \\
\hline Genital aphthosis & 2 \\
\hline Ocular manifestations & 2 \\
\hline Skin manifestations & 1 \\
\hline Pathergy phenomenon & 1 \\
\hline Vascular manifestations & 1 \\
\hline
\end{tabular}

Cyto-morphometric characteristics would be highly altered in the cells of buccal mucosa in case of chronic diseases associated with inflammation $\left({ }^{9}\right.$.

Exfoliative cytology is a technique characterized by being conservative not causing any invasion on tissues in addition to the possibility of the specimens taken to be determined in qualitative 
and quantitative manners (10) .Quantitative characteristics such as cytoplasmic area (CA), nuclear area (NA), and the nuclear to cytoplasmic ratio (N/C) have been found to be noticeable during the process of diagnosis of oral cavity lesions (11). The Measurement of those morphometric features (nuclear, cytoplasmic areas and nuclear /cytoplasmic ratio) can be made manually with the help of ocular grids, or even objectively using a digital image analysis that can trace microscopic images to be measured reproducibly and objectively ${ }^{(12)}$. There are many factors affecting the cell cytomorphology which is already collected from the buccal mucosa. Systemic illness such as diabetes Type $1 \& 2$, alcohol intake, and all types of anemia can be regarded as some of such factors ${ }^{(13)}$,not forgetting the role of infectionrelated diseases (14). The effects of Behçet's disease on buccal mucosal cells have been documented on some previous studies (15-16).

Quantitative exfoliative cytology has been used in this study so that the effect of Behçet's disease can be assessed in the buccal mucosa of cases in terms of estimating nuclear area (NA), the cytoplasmic area (CA), and nuclear cytoplasmic ratio (N/C) to be compared with those of buccal mucosa of control group.

\section{MATERIAL AND METHODS}

The "case control" study was performed on two groups. The "study group" consisted of $25 \mathrm{BD}$ patientss whose diagnosis was provided at the Dermatology out-patient clinic in Baghdad Teaching Hospital in Medical city. The "control group" was composed of 25 healthy counterparts who got a health examination periodically. The study was done in accordance with the
"Local Ethics Committee for human research" after obtaining a written consent from all the participants.

\section{Criteria of selecting Patients}

A questionnaire had been completed for each subject for collecting data regarding their past medical history, diabetes mellitus, radiotherapy, smoking habits, alcohol consumption, and drug addiction, in order not to be included in this study.

\section{The process of Sampling.}

All the samples of the "study subjects" have been collected over a period of 4 months after the diagnosis being confirmed according to ICBD. In order to remove debris, the patient was asked to rinse with tap water. A piece of gauze was usually used for having a dry oral mucosa. The samples were collected from the buccal mucosa using a disposable Pap smear brush. The freshlyobtained smears were streaked on labeled-glass slides and then the fixation would be in $95 \%$ ethyl alcohol. Papanicolaou was used as a staining technique for the examination of cytomorphometric.

\section{The Examination of Cytomorphometric.}

It should be stated that nuclear area (NA), cytoplasmic area $(\mathrm{CA})$, ratio of nuclear area to cytoplasmic area $(\mathrm{N} / \mathrm{C})$ were included in the study parameters examined. The digital photographs, taken from the slides by means of light Microscope with amounted digital camera (0.3M Pixel VCE-PW1), were used to perform cytological analysis.

NA and CA were measured on digital images using an image analysis software called "motic images plus 3.0(x86)" surrounding the nuclear and cytoplasmic cell boundaries (Fig. 1).

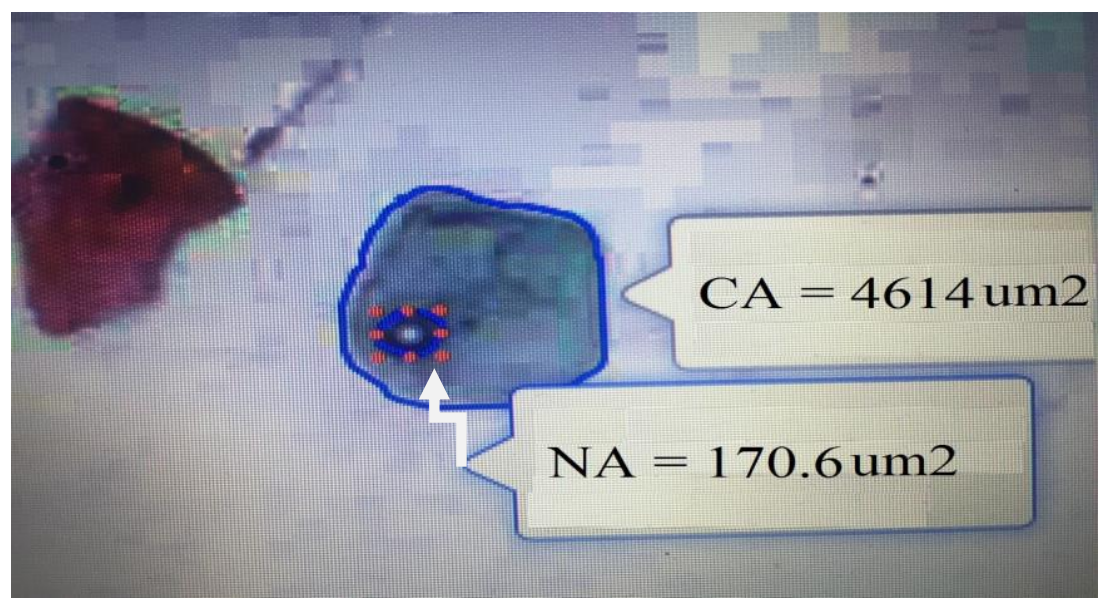

Figure 1: The encirclement of boundaries of the cytoplasm and the nucleus of then suprabasal cells case on digital images (x20) 


\begin{abstract}
Statistical Analysis
In this study, the statistical analysis has been accomplished by SPSS version 23 software in addition to Microsoft Excel. The "Semimov Kolmogorov" test was used to examine the distribution of current variables whether they are normal or not. The Measurement of central tendency was done with a median and more accurately the inter-quarter range. Furthermore, the non-parametric "Mann Whitney" test was used to show the difference in the significance between both, the study and control groups.
\end{abstract}

\section{RESULTS}

In the present study, the age of BD patients ranged from 25- 56 years with a mean of 38 years, and 28.1 years for "control subjects" $(p=0.001)$. Also, the gender distribution was nearly comparable in both groups with statistically significant differences $(p=0.001)$. Male gender was more predominant than the female in both groups, and the ratio of male/female in BD cases=1.7:1 while it was 2.1:1 in healthy subjects as shown in table 2 .

The clinical symptom found in BD patients with the highest frequency was ocular involvement $(80 \%)$ while the lowest frequency was neurological symptoms (4\%). In addition, all BD cases had oral ulcers but none of them were recorded to have cardiac or pulmonary symptoms as shown in table 3 .

Using the digital manner to analyze all the cells collected from healthy controls and BD cases is shown in table 4 which shows that the median of CA concerning BD cases is smaller (4980.7 $\left.u^{2}\right)$ than that of healthy subjects $\left(11530.7 \mathrm{um}^{2}\right.$ ) .

Similarly, the nuclear area of Behçet's disease cases was $157.6 \mathrm{um}^{2}$ compared to $388.5 \mathrm{um}^{2}$ of that of healthy volunteers. However, the ratio of both groups showed nearly comparable results.

\section{DISCUSSION}

The major goal of the study was to determine and compare between the quantitative assessments of cytomorphometrical parameters of buccal mucosal cells of BD patients with healthy controls.

The mean age in the current study of BD patients was 38 years, and this findings is in line with other Iraqi studies ${ }^{(17,18)}$. In addition, there was another study reporting the same mean age ${ }^{(19)}$.
It was found in present study that the male gender was more predominant than that of female in BD cases and the ratio of male/female was 1.7:1. A similar predominance in gender and nearly comparable male/female ratio $2.9: 1$ to the current study was recorded ${ }^{(17)}$. Nevertheless, the study done by Zouboulis, 1999 found that the male and female in BD cases were frequently equal $^{(20)}$. The reason behind those contradictory findings that the gender ratio was different according to geographical area ${ }^{(21)}$.

It has been found that in the current study, all cases with BD had recurrent aphthous stomatitis. The clinical symptoms in a decreasing order of frequency are ocular involvement with $80 \%$, genital ulcerations with $60 \%$, skin and articular lesions $40 \%$, and $36 \%$ respectively, and scarcely neurological symptoms. None of BD cases had pulmonary or cardiac symptoms.

With regard to clinical frequency, nearly similar findings were found on some studies ${ }^{(3,20)}$. But those studies slightly differed from other findings recorded on Italian BD cases and on Egyptian BD cases ${ }^{(22,23)}$. However, both of them revealed the same oral and genital frequency but the ocular and cutaneous lesions seldom occurred. The difference in study groups ethnically is the cause for varied BD clinical frequencies in addition to the probability of the severity of the disease, and the size of samples.

In the present study, it was found that the cytomorphometrical variables such as cytoplasmic area (CA) and nuclear area( NA) of oral epithelial cells of $\mathrm{BD}$ cases reduced significantly when compared with those of "control group" ,but the ratio was still comparable in both groups .

The present findings have confirmed the findings reported by "Erol Aktunc et al." in 2016 who showed comparable results to present study ${ }^{(15)}$. However, another study done by "Kara et al.". Revealed comparable results with regard to the reduction of cytoplasmic volume and nuclear volume. The ratio also reduced, not still constant like what happened in present study, and the relative differences in outcomes may be related to using smaller sample size or different quantitative cytomorphometric parameters such as cytoplasmic volume (CV) and nuclear volume (NV) applying a specific formula on variables taken from digital images of light microscope (two dimensions) ${ }^{(16)}$.

BD cases, unlike healthy volunteers, have elevating oxidative stress which is regarded as a biomarker for $\mathrm{BD}$ causing changes in 
cytomophometric characteristics in $\mathrm{BD}$ patients (24-25).

This study determined the cytomorphometrical analysis quantitatively of oral epithelial cells parameters in Behçet's disease cases to be compared with normal population. In conclusion the quantitative characteristics of cytomorphometry were affected and altered by Behçet's disease as a main factor for this alteration , and these alterations are detectable by cytomorphometric analysis through exfoliative cytology. The cytomorphometric view of mucosal cells in BD patients presented in this study will contribute to the understanding of the effects of BD on the oral mucosa.

\section{REFERENCES}

1. Arayssi T, Hamdan A . new insights into the pathogenesis and therapy of Behcets disease. Curr Opin Pharmacol 2004; 4: 183-188.

2. Alpsoy E, Zouboulis C, Ehrlich GE. "Mucocutaneous lesions of Behcet's disease." YMJ 2007; ( 48)4: 573-585.

3. Davatchi F, Chams-Davatchi C, Shams H, Shahran F, Nadji A, Akhlaghi M, Faezi T, Ghodsi Z, Sadeghi Abdollahi B, Ashofeh F, Mohasham N, Kavosi H. Masoumi "Behcets disease: epidemiology, clinical manifestation, and diagnosis. "M Expert Rev clin Immunol, 2014; 13: 57-65.

4. Sakane T, Takeno M, Suzuki N, NandInaba G. Behcets disease.N Engl Med 1999; 341:12841291.

5. Hamdan A, Mansour W, Uthman I, Masri A, Nasr F, Arayssi T. Behcets disease in Lebanon: clinical profile, severity and two-decade comparison. Clin Rheumatol 2006 ; 25: 364-367.

6. Kural - Seyahi E, Fresko I, Seyahi N, Ozyazgan Y, Mat C, Hamuryudan V, Yurdakul S, Yazaci H. The long-term mortality and morbidity of Behcet syndrome: a2-decade outcome survey of 387 patients followed at a dedicated center. Medicine (Baltimore) 2003; 82: 60-76.

7. Remmers E, Cosan F, Kirino Y, Ombrello M, Abaci N, Satorius C, Le JM, Yang B, Korman BD, Cakiris A, Aglar O, Emrence Z, Azakili H, Ustek D, Tugal - Tutkun I, Akman - Demir G, Chen W, Amos CL, Dizon MB, Kose AA, Azizlerli G, Erer B, Ollieirw WE, Wallace GR, Gadina M, Kastnrr DL, Gul A. Genome-wide association study identifies variants in the MHC class 1, IL10, and IL23R-IL12RB2 regions associated with Behcets disease.Nat Genet 2010 ; 42: 698-702

8. International Study Group for Behcet's Disease, "Criteria for diagnosis of Behcet's disease," The Lancet1990; (335) 8697: 1078-1080.

9. Jajarm HH, Mohtasham N, Rangiani A." Evaluation of oral mucosa epithelium in type 2 diabetic patients by an exfoliative cytology method, "J Oral Sci 2008; 50(3): 335-340.
10. Woyceichoski IE ,de Arruda EP, Resende LG, Machado MA, Greqio AM, Azevedo LR , de lima AA. Cytomorphometric analysis of crack cocaine effects on the oral mucosa. Oral Surg Oral Med Oral Pathol Oral Radiol Endod 2008; 105: 745749.

11. Ramesh T, Mendis BRRN, Ratnatunga N . That-til RO: Cytomorphometric analysis of squames obtained from normal oral mucosa and lesions of oral leukoplakia and squamous cell carcinoma $\mathbf{J}$ Oral Pathol Med 1998; 27: 83-86.

12. Meijer GA, Belien JAM, Diest VPJ, Baak JPA. "Image analysis in clinical pathology. " JCP 1997; 50: 365-370.

13. Ogden GR, Wight AJ, Rice P. Effect of alcohol on the oral mucosa assessed by quantitative cytomorphometry J Oral Pathol Med 1999; 28: 216-20.

14. Bektas ZSOz, Battal SF, Atmaca H, Ermis B. "Nuclear morphometric and morphological analysis of exfoliated buccal and tongue dorsum cells in type-1 diabetic patients, "JOC 2014; 31(3): 139-143.

15. Aktunc E, Oz ZS, Bektas S, Altinyazar C, Kcca R, Bostan S. "Cytomorphometric Characteristics of Buccal Mucosal cell in Behcets disease patients "Hindawi publishing corporation, Anal cell pathol 2016; 5 pages.

16. Kara A, Selli J, Bilen H, Eyerci N. "Effects of immunosuppressive drugs on oral mucosa in patients with Behcets disease: cytomorphological and cytopathological assessment. "Turk J Med Sci January 2016; 46 (1): 145-51.

17. Sharquie KE, AL-Araji A, Hatem A. Oral pathergy test in Behcet disease. $\mathrm{Br} \mathrm{J}$ Dermatol 2002; 146(1):168-9.

18. AL-Rawi ZS, Nada AH. Prevalance of behcets disease among Iraqis. Adv Exp Med Biol 2003; 528: 37-41.

19. Yazici H, Fresko I, Yarddkul S. Behcet syndrome: disease manifestations management, and advances in treatment. Nat clin Prect Rheumatol 2007; 3: 148-55.

20. Zouboulis CC. "Epidemiology of Adamantiades Behcets disease" Ann Med Interne 1999; 150 (6): 488-98.

21. Krause I, Yankerich A, Fraser A, Rosner I, Meder $\mathrm{R}$, Zisman D, Boulman $\mathrm{N}$, Rozenbaum $\mathrm{M}$, Weinberger A. "prevalence and clinical aspects of Behcet disease in nourth of Israel." Clin Rheumatol 2007; 26(4): 555-60.

22. Pipitone N, Boiad L, Olivieri I, Cantini F, Salvi F, Malatesta R, Corte R, Triolo G, Ferrante A, Filippini D, Paolazzi G, Sarzi-Puttini P, Restuccia G, Salvarani C. "clinical manifestation of behcet disease in 137 Italian patient: Results of multicenter study copyright", Clin EXP Rheumatol 2004, 22 (supp). 1.36: S46-S51.

23. EL-Najjar AR, Abo EL-Soud AM, Amar HA, AL Sayed M. "clinical characterstic and disease activity of Behcets disease patient in Zagazig Egypt. " Egypt Romatol 2015, 37(4): 191-196.

24. Bozkurt M, Y“uksel H, Em S, Oktayoglu P, Yildiz M, Akdeniz D, Nas K. "Serum prolidase enzyme activity and oxidative status in patients with 
Behcet's disease. "Redox Report 2014; (19)2: 5964.

25. Buldanlioglu S, Turkmen S, Ayabakan HB, Yenice N, Vardar M, Dogan S, Mercan E. "Nitric oxide, lipid peroxidation and antioxidant defence system in patients with active or inactive Behcet's disease." BJD 2005; (153) 3: 526-530.

Table 2: Age and gender distribution

\begin{tabular}{|l|c|c|}
\hline \multicolumn{2}{|c|}{ Control group } & BD group \\
\hline Age & $18-45$ & $25-56$ \\
\hline Range & 28.1 & 38 \\
\hline Mean & 1.5 & 1.9 \\
\hline SE & \multicolumn{1}{|c|}{} \\
\hline Gender & 8 & 9 \\
\hline Female & 17 & 16 \\
\hline Male & 25 & 25 \\
\hline Sum & & \\
\hline
\end{tabular}

$\mathrm{P}$ value $<0.001$

Table 3: Clinical Manifestation of Behçet's disease Cases

Clinical Manifestation

SUM =25

\begin{tabular}{|l|l|l|}
\hline & N & $\%$ \\
\hline Gentile Ulcers & 15 & 60 \\
\hline Ocular Lesions & 20 & 80 \\
\hline Articulal symptoms & 2 & 36 \\
\hline Skin lesions & 10 & 40 \\
\hline Neurological symptoms & 1 & 4 \\
\hline Gastrointestinal symptoms & 4 & 16 \\
\hline
\end{tabular}

Oral Ulcers $100 \% \quad$ No Cardiac symptoms No Pulmonary symptoms

Table 4: Cytomorphometrical analysis of Behçet's disease case group and Control group

\begin{tabular}{|c|c|c|c|}
\hline & Control group & BD group & \\
\hline \multicolumn{3}{|l|}{ Cytoplasmic area } & $\mathrm{P}=<0.001$ \\
\hline Range & $9417.9-14775$ & $3440-5924.7$ & \\
\hline Median & 11530.7 & 4980.7 & \\
\hline Mean rank & 87.7 & 15.6 & \\
\hline \multicolumn{3}{|l|}{ Nuclear area } & $\mathrm{P}=<0.001$ \\
\hline Range & $259.5-452.8$ & $121-197.5$ & \\
\hline Median & 388.5 & 157.6 & \\
\hline Mean rank & 88 & 42.8 & \\
\hline \multicolumn{3}{|l|}{ N/C ratio } & $\mathrm{P}=<0.92 \mathrm{NS}$ \\
\hline Range & $0.024-0.04$ & $0.024-0.049$ & \\
\hline Median & 0.032 & 0.033 & \\
\hline Mean rank & 72.2 & 72.8 & \\
\hline
\end{tabular}

الخلاصة

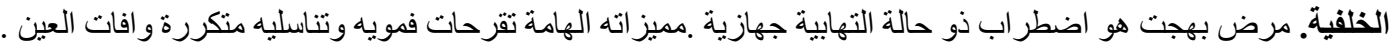

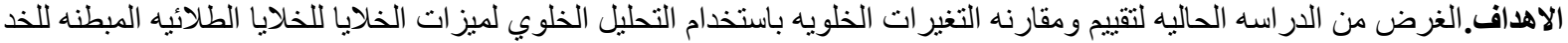

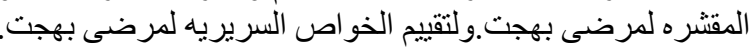

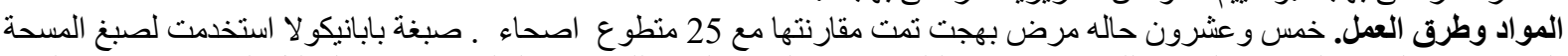

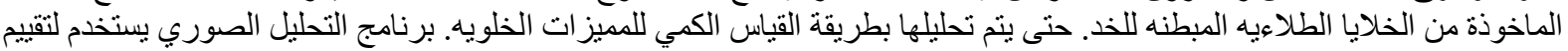

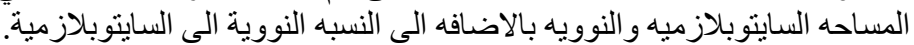

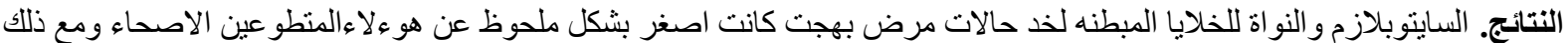

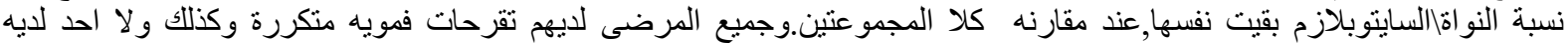
اعر اض قلبيه او رئوياه. الاستتتاجات.تقنيات "تقنثير الخلايها" و "تحليل القياس الكمي للميزات الخلويه" لها القابليه لكثف التغيرات, حدثت بسبب مرض بهجت

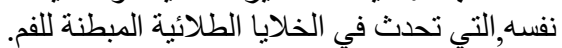

